\title{
Enhanced green fluorescent protein-mediated synthesis of biocompatible graphene
}

\author{
Sangiliyandi Gurunathan ${ }^{1,2 *}$, Jae Woong Han ${ }^{1}$, Eunsu Kim', Deug-Nam Kwon ${ }^{1}$, Jin-Ki Park ${ }^{3}$ and Jin-Hoi Kim
}

\begin{abstract}
Background: Graphene is the 2D form of carbon that exists as a single layer of atoms arranged in a honeycomb lattice and has attracted great interest in the last decade in view of its physical, chemical, electrical, elastic, thermal, and biocompatible properties. The objective of this study was to synthesize an environmentally friendly and simple methodology for the preparation of graphene using a recombinant enhanced green fluorescent protein (EGFP).

Results: The successful reduction of GO to graphene was confirmed using UV-Vis spectroscopy, and FT-IR. DLS and SEM were employed to demonstrate the particle size and surface morphology of GO and EGFP-rGO. The results from Raman spectroscopy suggest the removal of oxygen-containing functional groups from the surface of GO and formation of graphene with defects. The biocompatibility analysis of GO and EGFP-rGO in human embryonic kidney (HEK) 293 cells suggests that GO induces significant concentration-dependent cell toxicity in HEK cells, whereas graphene exerts no adverse effects on HEK cells even at a higher concentration (100 $\mu \mathrm{g} / \mathrm{mL})$.

Conclusions: Altogether, our findings suggest that recombinant EGFP can be used as a reducing and stabilizing agent for the preparation of biocompatible graphene. The novelty and originality of this work is that it describes a safe, simple, and environmentally friendly method for the production of graphene using recombinant enhanced green fluorescent protein. Furthermore, the synthesized graphene shows excellent biocompatibility with HEK cells; therefore, biologically synthesized graphene can be used for biomedical applications. To the best of our knowledge, this is the first and novel report describing the synthesis of graphene using recombinant EGFP.
\end{abstract}

Keywords: Enhanced green fluorescent protein, Graphene oxide, Graphene, Human embryonic kidney 293 cells, Cell viability, Membrane leakage, Oxidative stress

\section{Background}

Graphene has a two-dimensional (2-D) nanostructure with a single layer of carbon atoms and has attracted much interest in recent years because of its unique mechanical, thermal, catalytic, electronic, optical, and biological properties [1-4]. Graphene and graphene-based materials have been widely used in several applications including bio-sensing [5], antibacterial compositions [6-8], drug delivery [9], tissue scaffolds [10], catalysis [11], and energy storage [12]. The production of graphene in large quantities using an environmentally friendly approach is essential but also a significant challenge [13].

\footnotetext{
* Correspondence: gsangiliyandi@yahoo.com; jhkim541@konkuk.ac.kr 'Department of Animal Biotechnology, Konkuk University, 1 Hwayang-Dong, Gwangin-gu, Seoul 143-701, South Korea

${ }^{2}$ GS Institute of Bio and Nanotechnology, Coimbatore, Tamil Nadu 641024, India

Full list of author information is available at the end of the article
}

Several methods have been established for the synthesis of graphene and its derivatives, including exfoliation of graphite (Gt) [14], flash reduction [15], hydrothermal dehydration [16], mechanical exfoliation [3], epitaxial growth [17], photocatalysis [18], and photodegradation [19]. Although several methods are available for the preparation of graphene, solution-based chemical reduction of graphene oxide (GO) to graphene is considered one of the most efficient methods for low-cost and large-scale production of graphene [13]. Reduction of GO by chemical methods seems to be promising, because of the low cost and potential for large-scale production. Such methods are also appropriate for chemical modification and subsequent processing. However, in chemical methods, the use of hydrazine and hydrazine derivatives as strong reducing agents for the formation of graphene can be toxic or explosive, resulting in challenges for large-scale production. The resulting graphene 
also possesses very limited solubility or even irreversible agglomeration during preparation in water and most organic solvents unless capping reagents are used owing to the strong $\pi-\pi$ stacking tendency between rGO sheets $[20,21]$. To overcome the aggregation and solubility problems, several polymers or surfactants have been used, such as poly(N-vinyl-2-pyrrolidone) [22], poly(sodium-4-styrene sulfonate) [23], poly(allylamine) [24], and potassium hydroxide [25]. Recently, Akhavan et al. [26] demonstrated a possible route for inexpensive mass production of highquality graphene sheets from natural and industrial carbonaceous wastes.

The toxicity of GO and graphene has been studied in various cell types such as neuronal cells [27], lung epithelial cells [28], fibroblasts [29], primary mouse embryonic fibroblast cells [30], and cancer cells [31], and the results vary across cell and material types.

Surface modification of graphene has been reported to alter its toxicity [31], with reduced GO and carboxylated graphene reported to be less toxic than GO or native graphene [32]. Single-layer GO sheets were found to be internalized and sequestered in cytoplasmic, membranebound vacuoles in human lung epithelial cells and fibroblasts, with toxicity induced at concentrations above $20 \mu \mathrm{g} / \mathrm{mL}$ after $24 \mathrm{~h}[27,29]$. Sanchez et al. [4] reported that graphene-family nanomaterials (GFNs) can be either benign or toxic to cells, and that the biological responses depend on layer number, lateral size, stiffness, hydrophobicity, surface functionalization, and concentration. In addition, the biocompatibility and cytotoxicity depend on the type of reducing agent used for the functionalization of GO.

Graphene has been used as a possible biocompatible nanocarrier for delivering drugs [33] and also as a functional biomaterial. Sun et al. [9] reported that non-toxic PEGylated nano-graphene oxide could deliver waterinsoluble cancer drugs. Fan et al. [34] showed that graphene/chitosan composites were biocompatible in L929 cells and that the absence of metallic impurities in graphene sheets makes them potential candidates as scaffolds for tissue engineering. Furthermore, Chen et al. [35] reported that graphene oxide (GO)/ultra-high-molecularweight polyethylene (GO/UHMWPE) composites showed remarkably enhanced hardness and slightly improved yield strength compared with pure UHMWPE. The addition of small amounts of GO did not affect the attachment and proliferation of MC3T3-E1 osteoblasts cultured on GO/UHMWPE composite surfaces, indicating its excellent biocompatibility. Akhavan et al. [36] reported size-dependent cyto- and genotoxic effects of reduced graphene oxide nanoplatelets (rGONPs) rGONPs on cells. A cell viability test showed significant cell death on treatment with $1.0 \mu \mathrm{g} / \mathrm{mL}$ rGONPs with an average lateral dimension (ALD) of $11 \pm 4 \mathrm{~nm}$, whereas $\mathrm{rGO}$ sheets an ALD of $3.8 \pm 0.4 \mu \mathrm{m}$ exhibited a significant cytotoxic effect only at the high concentration of $100 \mu \mathrm{g} / \mathrm{mL}$ after $1 \mathrm{~h}$ of exposure time. Akhavan et al. [37] demonstrated the size-dependent cytotoxic and genotoxic effects of reduced graphene oxide nanoplatelets on human mesenchymal stem cells (hMSCs). Furthermore, Akhavan et al. [38] used ginseng extract-reduced GO to differentiate stem cells. Park et al. [39] used graphene-as a substrate to promote human neural stem cell adhesion and differentiation into neurons. Lee et al. [40] reported that the strong non-covalent binding ability of graphene allows it to act as a pre-concentration platform for osteogenic inducers, which accelerate the differentiation of mesenchymal stem cells (MSCs) growing on it toward the osteogenic lineage. Akhavan et al. [37] used graphene nanogrids as twodimensional selective templates for accelerated differentiation of human MSCs (hMSCs) isolated from umbilical cord blood into osteogenic lineages. The biocompatible and hydrophilic graphene nanogrids showed high actin cytoskeleton expression coinciding with the patterns of the nanogrids. Akhavan and Ghaderi [41] introduced a reduced graphene oxide ( $\mathrm{rGO}) / \mathrm{TiO}_{2}$ heterojunction film as a biocompatible flash photo stimulator for the effective differentiation of hNSCs into neurons. Graphene nanogrids on a $\mathrm{SiO}_{2}$ matrix containing $\mathrm{TiO}_{2}$ nanoparticles (NPs) were also applied as a photocatalytic stimulator to accelerate the differentiation of human neural stem cells (hNSCs) into two-dimensional neural networks [42].

Several environmentally friendly methods have been developed using various biomolecules such as ascorbic acid [43], amino acids [44], glucose [45], and bovine serum albumin [46] as reducing agents or stabilizers. In addition, microorganisms have also used to reduce $\mathrm{GO}$, including Shewanella [47], Escherichia coli [48,49], Pseudomonas aeruginosa [8], Bacillus marisflavi [50], and Ganoderma spp [21]. Some purified proteins have also been used for synthesis of graphene, such as melatonin [51], l-glutathione [52], and humanin [53]. Recently, the synthesis of graphene has been increased significantly because of the wide range of resources and availability of simple, cost-effective, and environmentally friendly approaches. The major problem encountered during the synthesis of nanoparticles using biomass is the isolation and purification of the nanoparticles from the biomass, which requires many downstream processing steps including sonication and ultracentrifugation to attain maximum yield [54]. Moreover, endotoxin may be present in the nanoparticles, which may limit the use of the nanoparticles in medical applications [55]. Therefore, this study attempted to use a recombinant protein.

Recombinant enhanced green fluorescent protein (EGFP) (Gene Bank Accession no. U57607) is a protein composed of 293 amino acid residues $(32.7 \mathrm{kDa})$ that has an isoelectric point of 6.2 and exhibits bright green fluorescence when exposed to light in the blue to ultraviolet range. 
EGFP has been widely used as a biological reporter to identify tissue and cells with target gene expression [56,57]. Previous studies showed no obvious detrimental effects of EGFP and no toxicity, i.e., it is biologically inert $[58,59]$. In addition, EGFP was selected here as a reducing and stabilizing agent for synthesis of graphene because it is a natural protein from the jellyfish Aequorea victoria and has been proven to be an excellent biological reporter [60]. Thus, without any other toxic reagents added, the raw material and reaction products are all environmentally friendly, which should increase the efficiency and largescale synthesis of graphene. Additionally, EGFP contains five cysteine amino acid residues, each containing a thiol group that can be oxidized to form the disulfide derivative cysteine, which functions as a nucleophile [61]. Protons have high binding affinity to oxygen-containing groups, such as hydroxyl and epoxide groups on $\mathrm{GO}$, resulting in the formation of $\mathrm{H}_{2} \mathrm{O}$ molecules $[27,62]$. The unique chemical structure of EGFP makes it not only an ideal reducing agent but also an effective capping agent. Therefore, we addressed the following objectives: first, the development of a simple, dependable, and environmentally friendly approach for synthesis of graphene using recombinant EGFP; second, the characterization of GO and EGFP-reduced GO; and finally, the evaluation of cellular responses of GO and EGFP-rGO in human embryonic kidney 293 cells.

\section{Results and discussion}

\section{Synthesis and characterization of EGFP-rGO}

As shown in Figure 1, EGFP-rGO was synthesized by a two-step process, including an oxidation step and an
EGFP-based reduction step. In the first step, graphene oxide was formed by the oxidation of graphite crystals according to a modification of the Hummers method [63]; the crystals were dispersible in water. In the second step, a stable black aqueous suspension was obtained through a chemical deoxidization process by using EGFP as both a reducer and a stabilizer. Similarly, Wang et al. [13] reported a simple method of reduction of GO to rGO using the natural polymer heparin as both a reducing agent and a stabilizer to produce a stable aqueous suspension of heparin-rGO sheets. Fan et al. [34] fabricated biocompatible graphene-reinforced chitosan composites in which chitosan was significantly reinforced by the addition of a small amount of graphene sheets. The graphene/chitosan composites were biocompatible in the L929 fibrosarcoma cell line.

The reduction of GO was confirmed using UV-vis absorption spectroscopy. As shown in Figure 1, the absorption peak of the GO dispersion was located at $230 \mathrm{~nm}$ with a shoulder peak at about $300 \mathrm{~nm}$, which was consistent with previous reports $[13,27,62]$. After the reduction process, the peak was red-shifted to $258 \mathrm{~nm}$ and the absorbance was increased dramatically in the entire spectral region. This result suggests that GO was reduced by EGFP and that the aromatic structure of graphene may be restored. Further evidence showed that the UV-vis absorption spectrum of GO was characterized by the $\pi-\pi^{*}$ of the $C=C$ plasmon peak at approximately $230 \mathrm{~nm}$ and a shoulder at approximately $300 \mathrm{~nm}$ that is often attributed to $n-\pi *$ transitions of the carbonyl groups $[62,64]$. With reduction by EGFP, the plasmon peak gradually red-shifted to approximately $258 \mathrm{~nm}$,

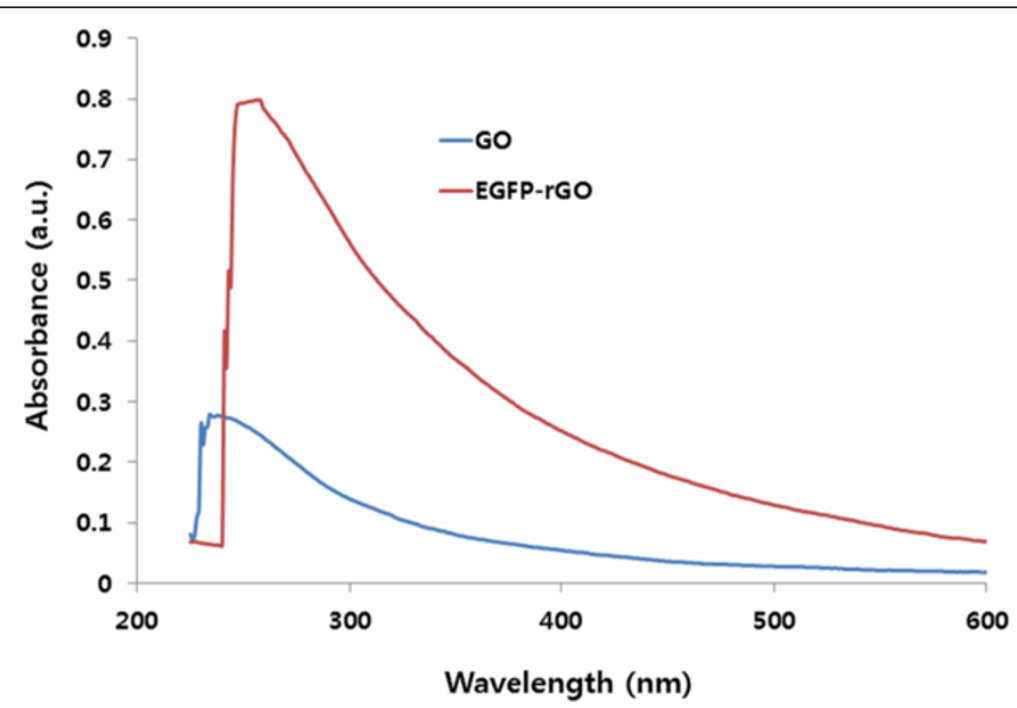

Figure 1 Synthesis and characterization of GO and EGFP-rGO by ultraviolet-visible spectroscopy. Spectra of GO exhibited a maximum absorption peak at approximately $230 \mathrm{~nm}$, which corresponds to a $\pi-\pi$ transition of aromatic $\mathrm{C}-\mathrm{C}$ bonds. The absorption peak for reduced $\mathrm{GO}$ was red-shifted to $258 \mathrm{~nm}$. At least three independent experiments were performed for each sample and reproducible results were obtained. Data from a representative experiment are shown. 
indicating the restoration of $\mathrm{sp}^{2}$ carbon and possible rearrangement of atoms [65]. Similar trends were also observed for the reduction of GO by L-ascorbic acid [43,66], L-cysteine [62], melatonin [51], heparin [13], dopamine [67], and humanin [53].

\section{FTIR spectra of GO and EGFP-rGO}

The reduction of oxygen-containing functional groups of GO by EGFP was confirmed by FT-IR spectroscopy. Figure 2 shows the FT-IR spectra of GO and EGFP-rGO. The presence of different types of oxygen-containing groups in graphene oxide was confirmed at $3440 \mathrm{~cm}^{-1}$ (O-H stretching vibrations), $1725 \mathrm{~cm}^{-1}$ (stretching vibrations from $\mathrm{C}=\mathrm{O}), 1225 \mathrm{~cm}^{-1}(\mathrm{C}-\mathrm{OH}$ stretching vibrations), and $1070 \mathrm{~cm}^{-1}$ (C-O stretching vibrations), as reported earlier [68,69]. In addition, the substitution of hydroxyl groups on the GO surface by carboxyl groups was confirmed by the $\mathrm{CH}_{2}$-stretching vibration at $2,920 \mathrm{~cm}^{-1}$ (lower spectrum) [70]. In contrast, the FT-IR spectrum of graphene completely differs from that of GO. The FTIR peak of EGFP-rGO showed $\mathrm{O}-\mathrm{H}$ stretching vibrations, stretching vibrations from $\mathrm{C}=\mathrm{O}, \mathrm{C}-\mathrm{OH}$ stretching vibrations, and $\mathrm{C}-\mathrm{O}$ stretching vibrations at 3440, 1725, 1225, and $1070 \mathrm{~cm}^{-1}$, respectively, indicating that GO was significantly reduced by the deoxygenation procedure. The intensities of absorption peaks corresponding to oxygen functional groups decreased and these functional groups almost disappeared. Altogether, these results clearly confirm that the oxygen-containing groups were removed during reduction using EGFP. These changes in EGFPrGO compared with GO in FT-IR spectra were identical with those of earlier reports that used various reducing agents such as hydrazine [14], vitamin C [66], L-cysteine [62], heparin [13], and humanin [53].

\section{XRD analysis of GO and EGFP-rGO}

To further characterize the crystal structures, the XRD patterns of the exfoliated GO and EGFP-rGO were studied. The characteristic peak of GO appears at $11.7^{\circ}$, corresponding to a $\mathrm{d}$-spacing of $0.76 \mathrm{~nm}$ resulting from the formation of hydroxyl, epoxy, and carboxyl groups (Figure 3). In contrast to GO, EGFP-rGO showed no peaks at $11.7^{\circ}$, which indicates that most of the oxygen functional groups of GO were removed. Compared with pristine graphite $\left(2 \theta=26.4^{\circ}\right)$, the diffraction peak of exfoliated GO moved to $11.7^{\circ}(002)$ with a layer-to-layer distance (d-spacing) of $0.76 \mathrm{~nm}$. This value was larger than the $\mathrm{d}$-spacing of pristine graphite $(0.34 \mathrm{~nm})$ because of the introduction of numerous oxygenated functional groups on the carbon sheets [13]. After the exfoliated GO was reduced by EGFP, the peak at $11.7^{\circ}$ disappeared, but a new diffraction peak appeared at $2 \theta=$ $25.8^{\circ}$ with a d-spacing of $0.36 \mathrm{~nm}$, which was closer to the typical (002) diffraction peak of graphite $\left(2 \theta=26.4^{\circ}\right.$, dspacing of $0.34 \mathrm{~nm}$ ). The higher interlayer spacing value of exfoliated GO resulted from the introduction of numerous oxygenated functional groups on the carbon sheets $[7,21,48]$. The data obtained from this experiment suggest that EGFP played an important role in the deoxygenation of GO and also that the reduction of GO by EGFP was consistent with earlier reports using various reducing agents including vitamin C [66], L-cysteine [62], heparin [13], and humanin [53].

\section{Size distribution analysis of GO and EGFP-rGO}

Size distribution analysis was performed to elucidate the state of GO and EGFP-rGO in an aqueous solution using DLS measurement [71] with a concentration of $250 \mu \mathrm{g} / \mathrm{mL}$. The average hydrodynamic diameter (AHD)

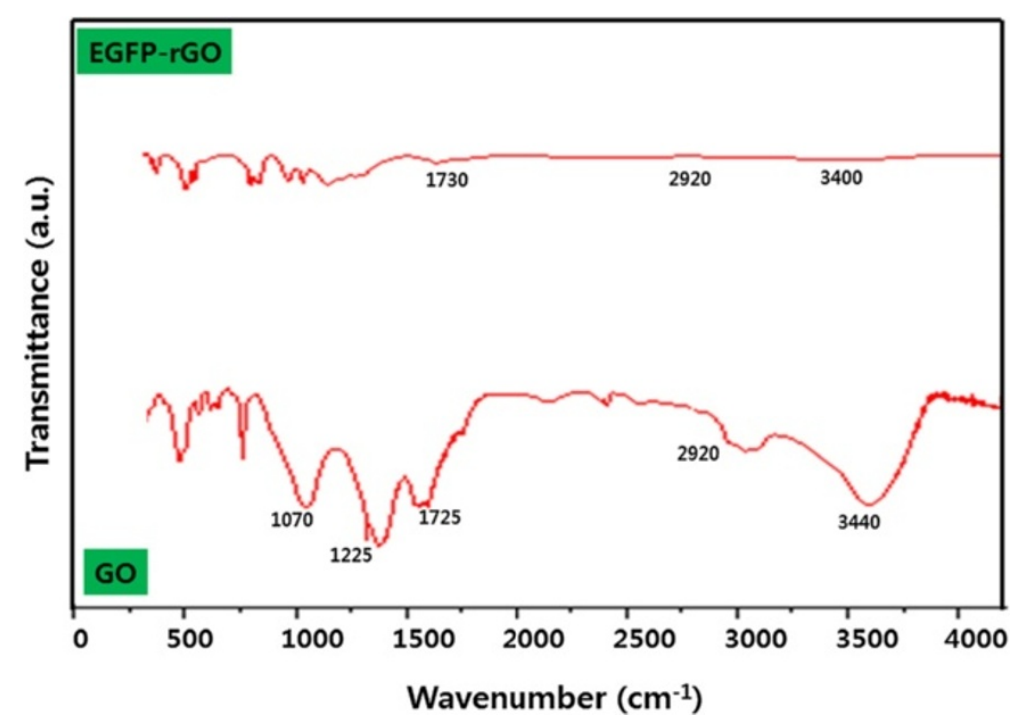

Figure 2 Fourier transform infrared spectroscopy spectra of GO and EGFP-rGO. 

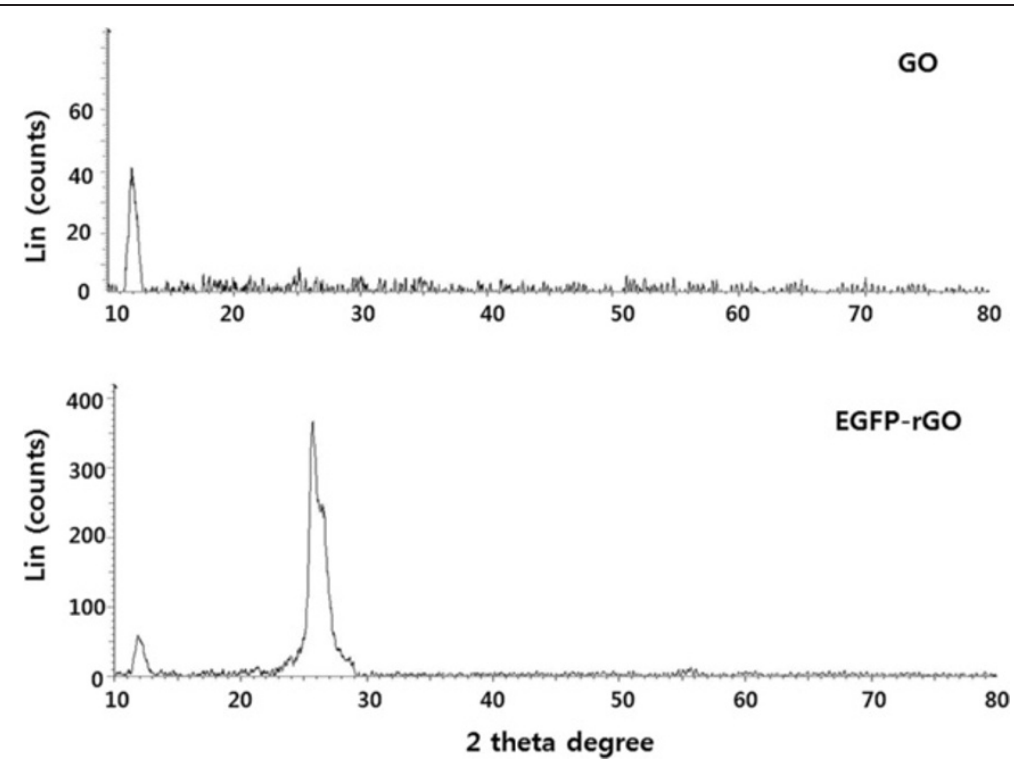

Figure 3 XRD patterns of GO and EGFP-rGO. In the XRD pattern of GO (top panel), the strong and sharp peak at $2 \theta=11.7^{\circ}$ corresponds to an interlayer distance of $7.6 \AA \AA$. EGFP-rGO (bottom panel) has a broad peak centered at $2 \theta=25.8^{\circ}$, which corresponds to an interlayer distance of 3.6 $\AA$. These XRD results are related to the reduction of GO by EGFP and the process of removing intercalated water molecules and oxide groups. At least three independent experiments were performed for each sample and reproducible results were obtained. Data from a representative experiment are shown.

of GO and EGFP-rGO was $2288 \pm 20 \mathrm{~nm}$ and $2607 \pm$ $32 \mathrm{~nm}$, respectively (Figure 4). However, after the reduction of GO with EGFP, the AHD increased and was relatively larger than that of GO. This obvious change of size distribution suggests that EGFP not only acted as a reducing agent to prepare $\mathrm{rGO}$ but also functionalized on the surface of the resulting rGO. Similar results were observed for heparin and biopolymer-functionalized reduced graphene oxide [13,72]. Graphene nanoplates functionalized with isocyanate showed the effective hydrodynamic diameter size of $560 \pm 60 \mathrm{~nm}$. Lammel et al. [73] reported that the hydrodynamic diameter of GO functionalized with carboxyl graphene nanoplatelets increased from 385 to $1,110 \mathrm{~nm}$. Liu et al. [74] reported that aqueously dispersed graphite (Gt), graphite oxide $(\mathrm{GtO})$, graphene oxide $(\mathrm{GO})$, and reduced graphene oxide (rGO) had sizes of 5,250, 4,420, 560, and 2,930 nm, respectively. A similar trend was observed for $\mathrm{GO}$ reduced by Pseudomonas aeruginosa [8], Bacillus marisflavi [50], Ginkgo biloba [70], and Ganoderma spp [21]. The size of EGFP-rGO was slightly larger than that of GO, indicating that EGFP not only acted as a reducing agent but also was functionalized on the surfaces of the resulting rGO, leading to an increased size [75]. Similarly, Wang et al. [13] found that the average size of heparin-reduced graphene oxide was larger than that of GO under the same experimental conditions. Altogether, our data and data from other groups suggest that EGFP used as a reducing agent plays an important role in increasing the size of rGO.

\section{Surface properties of GO and EGFP-rGO}

Zeta potential is an important factor for characterizing the dispersion stability of colloids because the magnitude and sign of the effective surface charge associated with the double layer around the colloid, and it directly influences the electrostatic interaction between different graphene sheets [76,77]. Zeta potential measurements were carried out in aqueous solutions of the GO and EGFP$\mathrm{rGO}$ in function of $\mathrm{pH}$ is important to determine the surface charge of the sheets (Figure 5). The results show that GO sheets are highly negative charged with an average $-29.7 \mathrm{mV}$ at $\mathrm{pH}$ range between 2 and 10 . This value is attributed to the presence of oxygen species at the surface of GO. On the contrary, EGFP-rGO, shows positive zeta potential values for the same $\mathrm{pH}$ range, which is suggest that the lower charge density of this type of graphene. Interestingly, recombinant proteins treated GO sheets resulted in the reduction and almost complete elimination of the oxygen functionalities at the surface of graphene materials.

Surface morphology analysis of GO and EGFP-rGO by SEM The surface morphology of the GO and EGFP-rGO samples was analyzed using SEM. As shown in Figure 6A, the GO samples contain several layers of sheets, and further the sheets are aggregated and crumpled sheets are closely associated with each other to form a continuous conducting network. The edges of the GO sheets appeared crumpled, folded, and closely restacked with one 


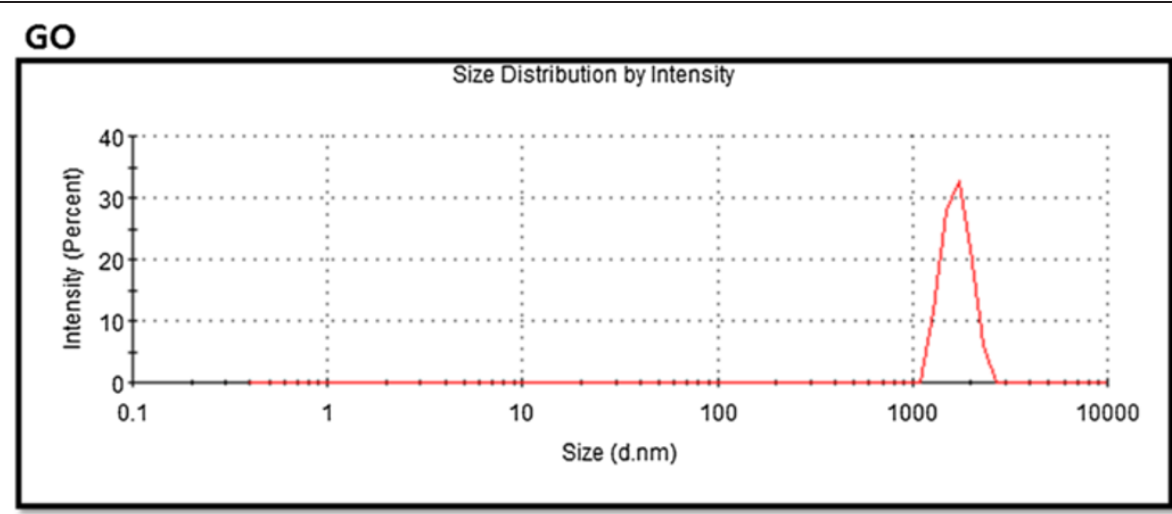

EGFP-RGO

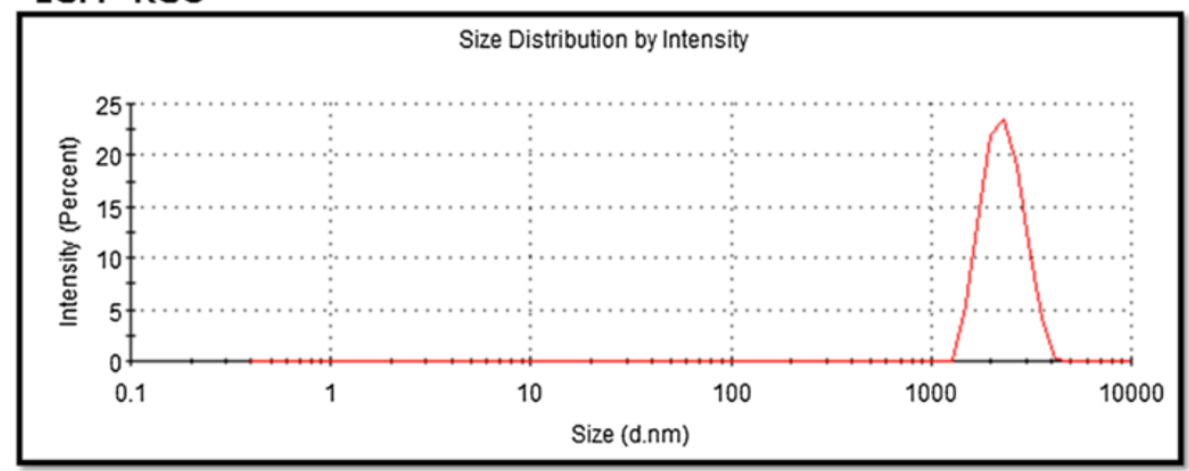

Figure 4 Size distribution analysis of GO and EGFP-rGO. Aqueous dispersions of GO and EGFP-rGO were characterized by DLS analysis using a particle size analyzer at the scattering angle $\theta=90^{\circ}$. The data show the average values from triplicate measurements. The sample concentrations were all $250 \mu \mathrm{g} / \mathrm{mL}$.

another because of the oxidation process [78]. Jeong et al. [79] reported that at higher concentrations, the surfaces of GO sheets have a soft-carpet-like morphology, possibly because of the presence of residual $\mathrm{H}_{2} \mathrm{O}$ molecules and hydroxyl or carboxyl groups attached to
GO. In contrast to GO, on SEM the EGFP-rGO samples resemble transparent and rippled silk waves (Figure 6B). $\mathrm{He}$ and Gao [80] reported that Gt appears to pile up in thick cakes, whereas GO is exfoliated into thin large flakes with wavy wrinkles. Previously, we observed on

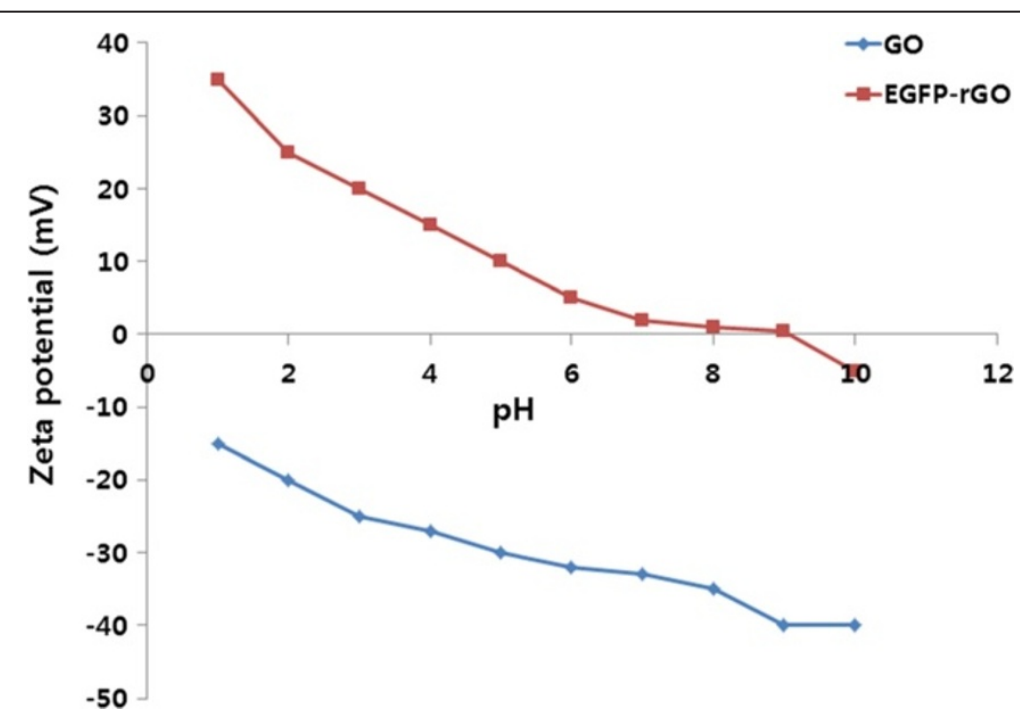

Figure 5 Zeta potential of as-prepared GO and EGFP-rGO as a function of $\mathrm{pH}$, in aqueous dispersions at a concentration of $\sim 0.05 \mathrm{mg} \mathrm{ml}^{-1}$. 


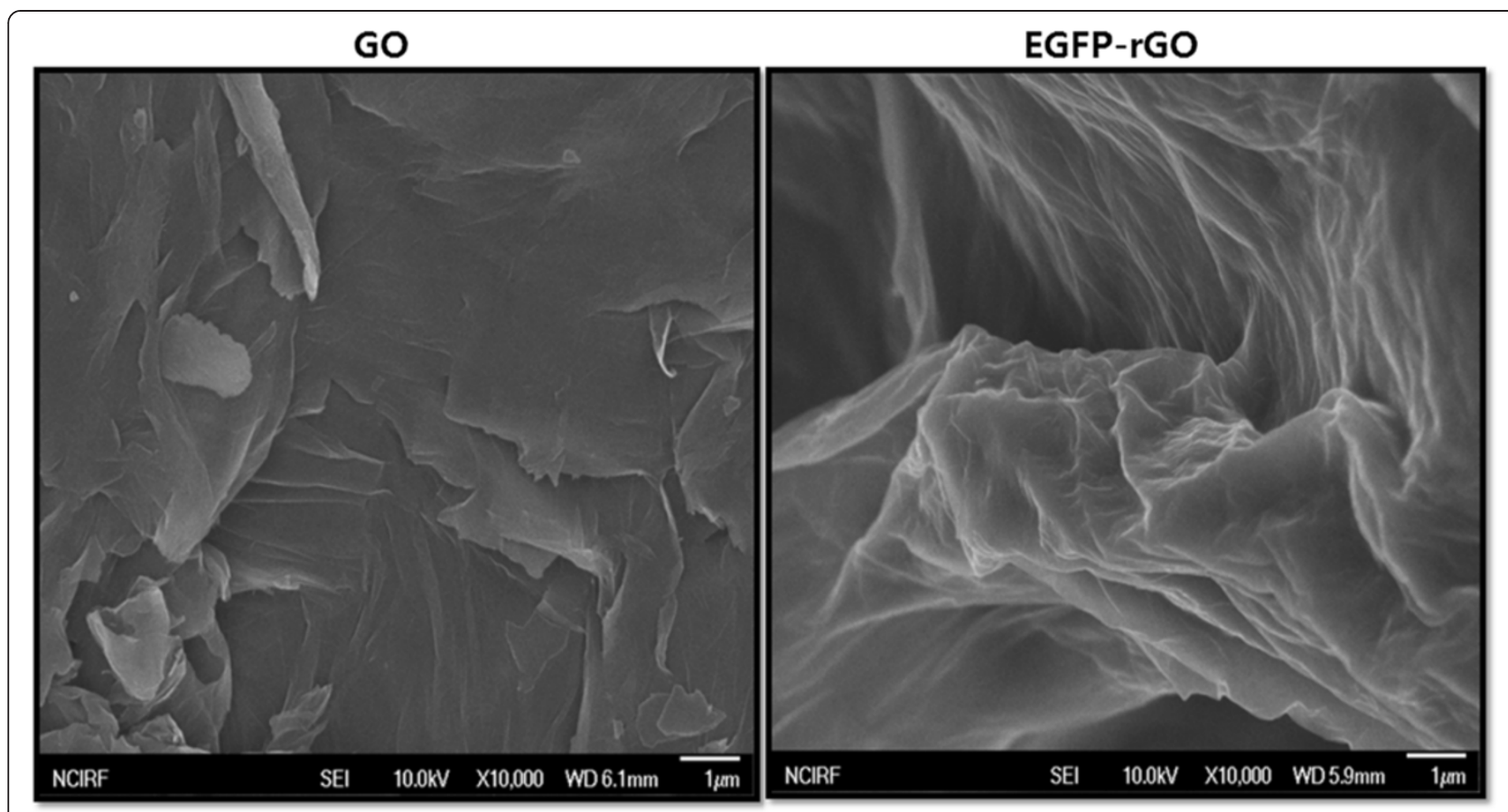

Figure 6 SEM images of GO and EGFP-rGO. Representative SEM images of GO and EGFP-rGO dispersions at $500 \mu \mathrm{g} / \mathrm{mL}$.

SEM that GO consisted of individual sheets closely associated with each other, with a silky and leaf-like structure, whereas Ginkgo biloba extract-reduced GO (Gb-rGO) sheets showed thin layers of nanosheets and were mainly comprised of larger, wavy forms [70]. The graphene sheets were found to possess a curled morphology consisting of a thin, wrinkled, paper-like structure, with fewer layers (approximately four layers) and a large specific surface area [81]. Graphene nanosheets were functionalized with long chains and polymers, resulting in coarse and hairy surfaces with blurry edges of the flakes [80]. Previously, we reported using SEM that GO was present as multilayered, wavy, folded flakes, whereas fungal extract-reduced graphene oxide showed several layers stacked on top of one another similarly to sheets of paper, with a silky, wrinkled, and flower-like curling morphology [70]. This difference in morphology between the folded, stacked structure of GO and transparent and rippled silk wave structure of graphene suggests that EGFP played an important role in the reduction of GO to graphene. The data obtained from this study suggest that synthesis of graphene using biological molecules was similar to that of graphene sheets prepared from Gt powder through oxidation followed by rapid thermal expansion in a nitrogen atmosphere [81].

\section{Raman spectroscopy analysis of GO and EGFP-rGO}

Raman spectroscopy is used to characterize the structural electronic properties of graphite and graphenebased materials $[21,82,83]$. Raman spectra are also used to measure induced enormous structural changes during chemical oxidation of pristine graphite and the reduction of $\mathrm{GO}$ to $\mathrm{rGO}$ [83]. In the Raman spectra, the $\mathrm{G}$ band resulting from first-order scattering of the $E_{2 g}$ phonons of $\mathrm{sp}^{2}$ carbon atoms and the $\mathrm{D}$ band originating from the breathing mode of k-point photons of $\mathrm{A}_{1 \mathrm{~g}}$ symmetry are the two main characteristic features of graphenebased materials [84-86]. In the Raman spectrum of GO, the $\mathrm{G}$ band is broadened and shifted to $1615 \mathrm{~cm}^{-1}$. In addition, the $\mathrm{D}$ band at $1359 \mathrm{~cm}^{-1}$ becomes prominent, indicating a reduction in the size of the in-plane $\mathrm{sp}^{2}$ domains, possibly because of extensive oxidation-induced defects in the sheets (Figure 7). The Raman spectrum of the $\mathrm{rGO}$ reduced by EGFP also contains both $\mathrm{G}$ and $\mathrm{D}$ bands located at 1607 and $1351 \mathrm{~cm}^{-1}$, respectively; however, the $\mathrm{D} / \mathrm{G}$ intensity ratio (2.149) is increased compared to that in GO upon reduction. This change suggests a decrease in the average size of the $\mathrm{sp}^{2}$ domains upon reduction of the exfoliated GO $[14,84]$.

The major effects of deoxygenation are the restoration of the $\mathrm{sp}^{2}$ network and the introduction of small and isolated aromatic domains, and these effects are responsible for the observed increase in the ID/IG ratio in rGO $[66,83,86,87]$. Wang et al. [82] suggested that the $G$ band is broadened and shifted upward to $1,595 \mathrm{~cm}^{-1}$, and the increased intensity of the D band at $1,350 \mathrm{~cm}^{-1}$ could be attributed to the significant decrease in the size of the in-plane $\mathrm{sp}^{2}$ domains resulting from oxidation and ultrasonic exfoliation, in addition to the partially ordered graphite crystal structure of graphene nanosheets. The 


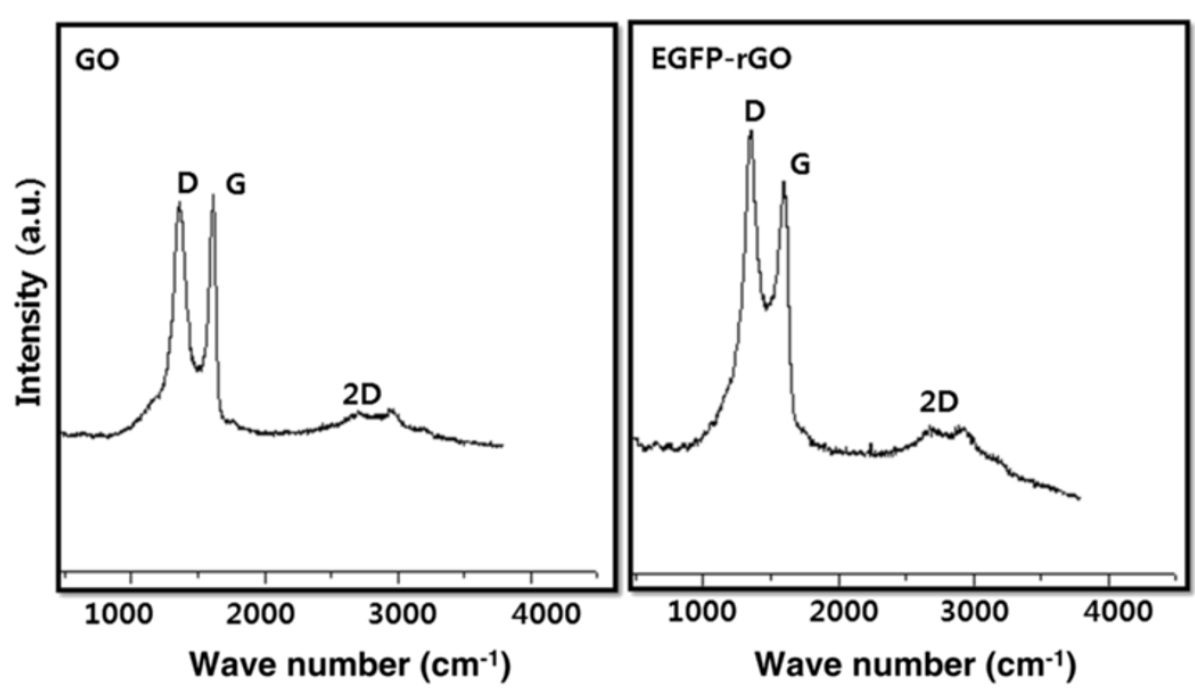

Figure 7 Raman spectroscopy analyses of GO and EGFP-rGO samples. Raman spectra were obtained using a laser excitation of $532 \mathrm{~nm}$ at a power of, $1 \mathrm{~mW}$. The figure shows representative Raman spectra of GO and EGFP-rGO samples after removal of the fluorescent background. The intensity ratios of the D-peak to the G-peak were 1.8 and 2.149 for GO and EGFP-rGO, respectively. At least three independent experiments were performed for each sample and reproducible results were obtained.

Raman spectra of graphene-based materials also show a two-dimensional (2D) band that is sensitive to the stacking of graphene sheets. It is well known that the two-phonon (2D) Raman scattering of graphene-based materials is useful to differentiate monolayer graphene from multilayer graphene as it is highly sensitive to the stacking of graphene layers $[14,88,89]$. Another characteristic of single-layer graphene is the relatively strong Raman intensity of the $2 \mathrm{D}$ band with respect to the G-band [90]. Usually, a Lorentzian peak for the $2 \mathrm{D}$ band of monolayer graphene sheets is observed at 2,679 $\mathrm{cm}^{-1}$, whereas this peak is broadened and shifted to a higher wave number in the case of multilayer graphene $[14,88,89]$. We observed the 2D band at $2699 \mathrm{~cm}$ ${ }^{-1}$, which is the same as the previously reported peak position for single-layer graphene $[90,91]$. Thus, our sample could consist of single-layer graphene flakes.

It should be noted that this ratio is higher than those reported for $\mathrm{rGO}$ produced using various reducing agents such as L-cysteine [62], dextran [92], baker's yeast [93], DTT [83,94], and $\mathrm{NaBH}_{4}$ [95]. The Raman spectroscopy analyses described here agree with those of previous studies that used various biomolecules and organisms to reduce GO to graphene, such as L-cysteine [62], Baker's yeast [93], heparin [13], Escherichia coli [48], P. aeruginosa [8], Humanin [53], Ganoderma spp [21], and Ginkgo biloba [70].

\section{Biocompatibility of GO and EGFP-rGO}

The HEK cell line has been extensively used as an expression tool for recombinant proteins [96]. Therefore, we used the HEK cell line as a model system to study the effect of GO and EGFP-rGO. Figure 8 shows the biocompatibility of EGFP-rGO in HEK cells assessed using the WST assay. GO exhibited concentrationdependent toxicity compared to untreated control cells, whereas EGFP-rGO-treated cells showed no significant toxicity when compared to untreated cells. Several studies have shown interactions between dispersed graphene and GO sheets in various cell types such as monolayer cultures of neuronal cells [27], lung epithelial cells [28], fibroblasts [30,47], and human breast cancer cells [21]. Single-layer GO sheets were found to be internalized and sequestered in cytoplasmic, membrane-bound vacuoles by human lung epithelial cells or fibroblasts, and they induced toxicity at concentrations above $20 \mu \mathrm{g} / \mathrm{mL}$ after $24 \mathrm{~h}$ $[28,29,94,97]$. Limited literature is available on the biocompatibility of graphene [4]. GFNs have been suggested to be useful as biosensors [98], tissue scaffolds [10], carriers for drug delivery and gene therapy [99], antibacterial agents $[7,8]$, and bio-imaging probes [27] because of their unique features over other types of nanomaterials, including their high specific surface area, which allows high-density biofunctionalization and drug loading. The results from our study indicate that EGFP-rGO can be used as a biocompatible material. Altogether, the results from our study and those from other groups suggest that EGFP-rGO can be used in various biomedical applications.

\section{Effect of EGFP-rGO on LDH leakage}

LDH (lactate dehydrogenase) is present in all types of cells and LDH leakage is a useful index for cytotoxicity on the basis of loss of membrane integrity, a hallmark of necrosis [100]. Based on the percentage of the maximum LDH release, in the present study EGFP-rGO was 


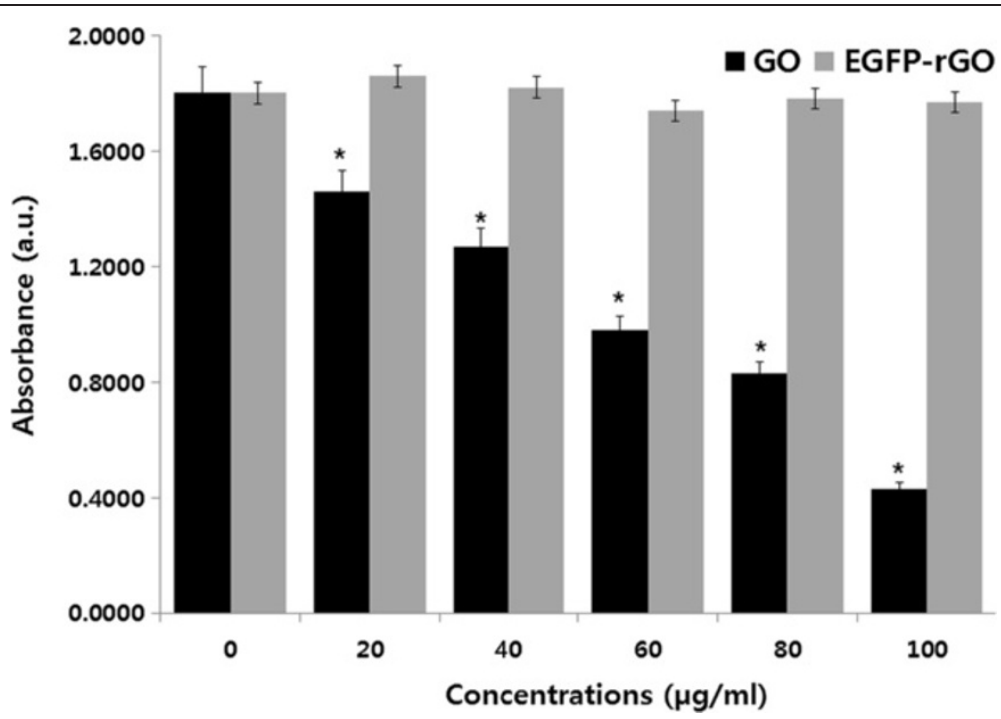

Figure 8 Effects of GO and EGFP-rGO on cell viability of human embryonic kidney 293 cells. Cell viability of human kidney cells was determined using WST-8 assay after 24 hours exposure to different concentrations of GO or EGFP-rGO. The results represent the means of three separate experiments, and error bars represent the standard error of the mean. GO- and EGFP-rGO-treated groups showed statistically significant differences from the control group by the Student's $t$-test $(P<0.05)$.

considered non-toxic to cells, whereas GO showed toxicity to the cells in a concentration-dependent manner when compared to untreated cells (Figure 9). Significant LDH release was observed after $24 \mathrm{~h}$ of exposure to GO at higher concentrations, whereas graphene had no effect on the release of LDH. Thus, the LDH assay results were consistent with the cell-viability assay results. The toxicity of graphene materials depends on their size, shape, composition, surface charge, and surface chemistry, in addition to the target cell type [101]. Zhang et al. [27] observed that graphene aggregates/agglomerates that had sedimented onto the surface of rat PC12 cells caused an increase in LDH leakage only at the highest exposure concentration $(100 \mu \mathrm{g} / \mathrm{mL})$. Our earlier findings also suggest that at higher concentrations, TEArGO has no significant toxicity in mouse embryonic fibroblast cells [102]. Therefore, EGFP-derived graphene is also biocompatible.

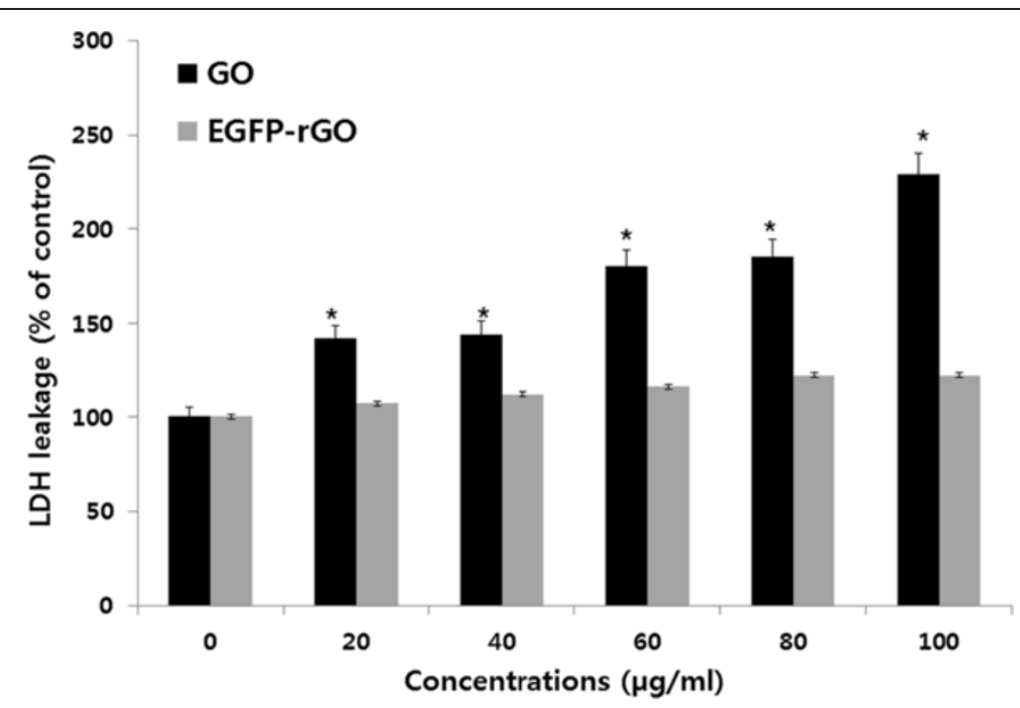

Figure 9 Effects of GO and EGFP-rGO on lactate dehydrogenase activity in human embryonic kidney 293 cells. Lactate dehydrogenase activity was measured at $490 \mathrm{~nm}$, using the cytotoxicity detection lactate dehydrogenase kit. The results represent the means of three separate experiments, and error bars represent the standard error of the mean. GO- and EGFP-rGO-treated groups showed statistically significant differences from the control group by the Student's $t$-test $(P<0.05)$. 


\section{Effects of EGFP-rGO on oxidative stress}

The DCF assay was performed to investigate the toxicity of nanomaterials attributable to ROS generation. Following exposure of HEK cells for $24 \mathrm{~h}$ to GO and EGFP$\mathrm{rGO}$, the state of oxidative stress in the cells was observed. As shown in Figure 10, the ROS generation increased in a concentration-dependent manner as the concentration of GO was increased, whereas EGFP-rGO had no significant impact, even at high concentrations, when treated cells were compared to untreated cells. These results were consistent with the results from the WST-8 assay and LDH assay, suggesting that toxicity in cells exposed to GO may result from oxidative stress mediated by ROS generation. It was previously shown that exposure to multiwalled carbon nanotubes (MWCNTs) resulted in a concentration-dependent cytotoxicity in cultured human embryonic kidney cells, which was associated with increased oxidative stress [103]. Zhang et al. [104] reported that surface functionalization (e.g., PEGylation) of single-walled carbon nanotubes (SWCNTs) reduced the ROS-mediated toxicological response in PC-12 cells. Induction of oxidative stress is considered to be one of the principal mechanisms underlying nanomaterial toxicity [105]. Lammel et al. [73] demonstrated that GO and carboxyl graphene nanoplatelets (CXYG) induce the generation of intracellular ROS in a concentration- and time-dependent manner in the human hepatocellular carcinoma cell line HepG2. GO-mediated cell death is caused by increased intracellular ROS levels originating from mitochondrial damage [73]. Stern et al. [106] suggest that several nanomaterials cause cell death through autophagy and lysosomal dysfunction. Qu et al. [107] reported that
ROS production was independent of surface modification on QDs and that ROS did not account for the cytotoxicity of QD-PEG- $\mathrm{NH}_{2}$ particles in J774A.1 cells. Recently, Wu et al. [108] investigated the toxicity of graphene oxide in Caenorhabditis elegans at adult day 10 and found that prolonged exposure to $0.1 \mathrm{mg} / \mathrm{L} \mathrm{GO}$ did not induce the noticeable intestinal autofluorescence or intestinal ROS production compared with the control; however, prolonged exposure to $10-100 \mathrm{mg} / \mathrm{L}$ GO resulted in intestinal autofluorescence and intestinal ROS production. Chong et al. [109] assessed the effect of graphene quantum dots (GQD) using various measures such as cell viability, cell apoptosis and necrosis, and LDH and ROS levels, and found that over $95 \%$ and $85 \%$ of HeLa cells and A549 cells, respectively, remained alive after $24 \mathrm{~h}$ of incubation with GQD-PEG, even when the GQD concentration increased to $160 \mu \mathrm{g} / \mathrm{mL}$. Furthermore, they suggested that the low cytotoxicity resulted from PEGylation or the inherent properties of the GQD sample. Graphene nanoparticles, depending on the synthesis method, can exhibit different morphologies, chemical properties, and physical properties. Earlier studies also suggest that graphene nanoparticles show diverse responses in cells and tissues depending on their morphology and synthesis method [110].

\section{Effect of EGFP-rGO on cell morphology}

Biocompatibility is important for the development of new nanomaterials for biological and biomedical applications [50]. In addition to the biochemical assays described above, we evaluated the morphology of the cells treated with GO and EGFP-rGO. The effect of EGFPrGO on cell morphology was determined using higher

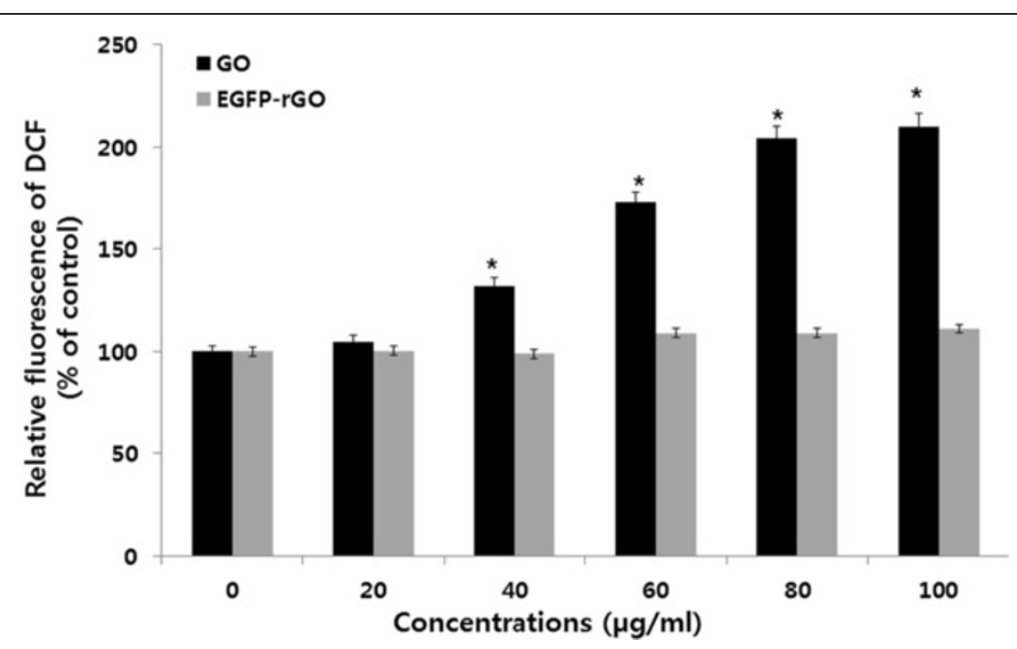

Figure 10 Effects of GO and EGFP-rGO on generation of ROS in human embryonic kidney $\mathbf{2 9 3}$ cells. The relative fluorescence of 2',7'-dichlorofluorescein was measured using a spectrofluorometer with excitation at $485 \mathrm{~nm}$ and emission at $530 \mathrm{~nm}$. The results represent the means of three separate experiments and the error bars represent the standard error of the mean. Treated groups $\mathrm{GO}$, showed statistically significant differences from the control group, as determined by Student's t-test $(P<0.05)$. 
concentrations of GO and EGFP-rGO $(100 \mu \mathrm{g} / \mathrm{mL})$, and the cells were seeded at the same density of $1 \times 10^{4}$ cells per plate. After 24 and $48 \mathrm{~h}$ of incubation, we observed the morphology of cells, and surprisingly, EGFP-rGO had no apparent effect; the cells were healthy (Figure 11); conversely, GO-treated cells were unhealthy, and the structure of the cells was contracted (Figure 11). Cheng et al. [67] reported that biopolymer-functionalized rGO exhibits an ultralow hemolysis ratio and significant cytocompatibility in human umbilical vein endothelial cells (HUVECs), even at a high concentration of $100 \mu \mathrm{g} / \mathrm{mL}$. Talukdar et al. [71] evaluated the effect of various types of graphene materials such as graphene nano-onions (GNOs), graphene oxide nanoribbons (GONRs), and graphene oxide nanoplatelets (GONPs) on the viability and differentiation of human mesenchymal stem cells (MSCs). They found that the cytotoxic effect was concentration-dependent but not time-dependent. In our study, concentrations lower than $50 \mu \mathrm{g} / \mathrm{mL}$ showed no significant differences compared to untreated controls. Our data suggest that EGFP-rGO at up to $100 \mu \mathrm{g} / \mathrm{mL}$ has no effect on cell viability, LDH, ROS generation, or on cell morphology. Our earlier studies demonstrated both cytotoxicity and biocompatibility of graphene materials in various cell types. Altogether, our findings and those of other research groups suggest that the cytotoxicity or biocompatibility of graphene materials is dependent on physicochemical properties such as the density of functional groups, size, and conductivity, in addition to the type of reducing agents used for the deoxygenation of GO, degree of functionalization, and cell type $[50,75]$. Finally, graphene materials prepared using recombinant EGFP could be useful for potential biomedical applications.

\section{Conclusion}

Commonly, the reduction of GO using chemical reducing agents is harmful to human health and the environment, and aggregation is another problem that occurs during the reduction process. Here, we show the synthesis of biocompatible graphene using recombinant EGFP. EGFP is one of the most widely used tools in biology because of its stability and lack of toxicity. In the present study, we explored the potential application of EGFP for a different purpose other than the tagging usually reported in the literature. We have developed a simple, dependable, and environmentally friendly method for the fabrication of reduced GO. Our findings suggest that GO induced significant concentration-dependent decreases in the viability of HEK cells, whereas graphene exerted no toxic effects on HEK cells at a concentration of $100 \mu \mathrm{g} / \mathrm{mL}$. Therefore, it is concluded that the use of a biological substrate in a simple and environmentally friendly approach for synthesis of graphene resulted in significant deoxygenation of suspended GO suspensions, thus providing a suitable substitute for chemical reducing agents and potentially enabling biomedical applications of graphene-based materials. This work may provide additional insight into graphene synthesis.

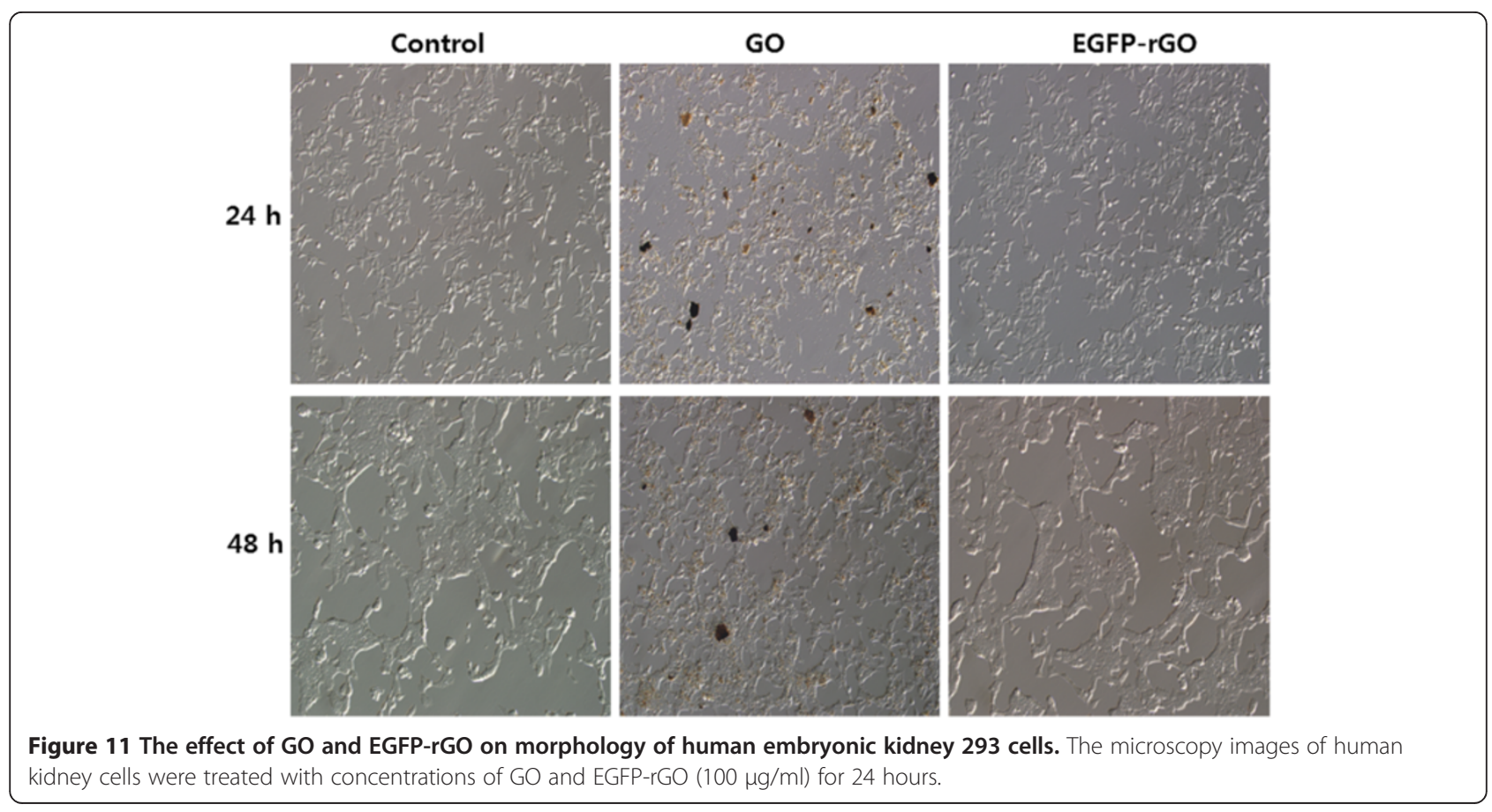




\section{Materials and methods Materials}

Gt powder, $\mathrm{NaOH}, \mathrm{KMnO} 4, \mathrm{NaNO}_{3}$ anhydrous ethanol, $98 \% \mathrm{H}_{2} \mathrm{SO}_{4}, 36 \% \mathrm{HCl}$, and $30 \% \mathrm{H}_{2} \mathrm{O}_{2}$ aqueous solution were purchased from Sigma-Aldrich (St Louis, MO, USA). Penicillin-streptomycin solution, trypsin-ethylenediaminetetraacetic acid solution, Dulbecco's Modified Eagle Medium (DMEM), and 1\% antibiotic-antimycotic solution were obtained from Gibco (Life Technologies, Carlsbad, CA, USA). Fetal bovine serum and the in vitro toxicology assay kit were purchased from Sigma-Aldrich. Enhanced green fluorescent protein was purchased from Bio-vision (Cat.No. 4999-100; Milpitas, California, USA).

\section{Synthesis of GO}

GO was synthesized as described previously [21,57]. In a typical synthesis process, natural Gt powder (2 g) was added to cooled $\left(0^{\circ} \mathrm{C}\right) \mathrm{H}_{2} \mathrm{SO}_{4}(350 \mathrm{~mL})$, and then $\mathrm{KMnO}_{4}(8 \mathrm{~g})$ and $\mathrm{NaNO}_{3}(1 \mathrm{~g})$ were added gradually while stirring. The mixture was transferred to a $40^{\circ} \mathrm{C}$ water bath and stirred for $60 \mathrm{~min}$. Deionized water $(250 \mathrm{~mL})$ was slowly added and the temperature was increased to $98^{\circ} \mathrm{C}$. The mixture was maintained at $98^{\circ} \mathrm{C}$ for a further 30 minutes and the reaction was terminated by the addition of deionized water $(500 \mathrm{~mL})$ and $30 \%$ $\mathrm{H}_{2} \mathrm{O}_{2}$ solution $(40 \mathrm{~mL})$. The color of the mixture changed to brilliant yellow, indicating the oxidation of pristine Gt to Gt oxide. The mixture was then filtered and washed with diluted $\mathrm{HCl}$ to remove metal ions. Finally, the product was washed repeatedly with distilled water until pH 7.0 was achieved, and the synthesized Gt oxide was further sonicated by ultrasonication for $30 \mathrm{~min}$.

\section{Preparation of EGFP-rGO}

Reduction of GO was performed as described previously $[21,41]$ with suitable modifications. Using GO as a precursor, EGFP-rGO was prepared using EGFP as both a reducing agent and a stabilizer. In a typical procedure, reduced $\mathrm{GO}(\mathrm{rGO})$ was obtained from the reaction of EGFP with GO. A mixed aqueous solution containing EGFP $(100 \mu \mathrm{g} / \mathrm{mL})$ and $\mathrm{GO}(1 \mathrm{mg} / \mathrm{mL})$ was ultrasonicated for $15 \mathrm{~min}$, and the mixture was maintained at $40^{\circ} \mathrm{C}$ for $1 \mathrm{~h}$. The mixture was then cooled to room temperature and ultrasonicated for a further $15 \mathrm{~min}$. After being vigorously stirred for $5 \mathrm{~min}$, the mixture was stirred in a water bath $\left(90^{\circ} \mathrm{C}\right)$ for $1 \mathrm{~h}$. The resulting stable black dispersion was then centrifuged and washed with water three times. A homogenous EGFP-rGO suspension was obtained without aggregation. Finally, the obtained EGFP-rGO sheets were redispersed in water before further use.

\section{Characterization of GO and EGFP-rGO}

GO and EGFP-rGO were characterized according to methods described previously [41]. UV-visible spectra were recorded using a WPA Biowave II spectrophotometer (Biochrom, Cambridge, UK). The particle sizes of the GO and EGFP-rGO dispersions were measured using a Zetasizer Nano ZS90 instrument (Malvern Instruments, Worcestershire, UK). X-ray diffraction (XRD) analyses were performed in a Bruker D8 DISCOVER X-ray diffractometer (Bruker AXS GmBH, Karlsruhe, Germany). The X-ray source was $3 \mathrm{~kW}$ with a $\mathrm{Cu}$ target, and high-resolution XRD patterns were measured using a scintillation counter $\left(\lambda=1.5406^{\circ} \mathrm{A}\right)$. The XRD was run at $40 \mathrm{kV}$ and $40 \mathrm{~mA}$, and samples were recorded at $2 \theta$ values between $5^{\circ}$ and $80^{\circ}$. The dried powder of $\mathrm{GO}$ and EGFP-rGO was diluted with potassium bromide and the Fourier transform infrared spectroscopy (FTIR) (Perkin Elmer Inc., USA) and spectrum GX spectrometry were recorded within the range of $500-4000 \mathrm{~cm}^{-1}$. A JSM6700 F semi-in-lens field emission scanning electron microscope was used to acquire SEM images. The solid samples were transferred to a carbon tape held in an SEM sample holder, and then the analyses were performed at an average working distance of $6 \mathrm{~mm}$. Raman spectra of GO and EGFP-rGO were measured using a WITEC Alpha300 laser with a wavelength of $532 \mathrm{~nm}$. Calibration was initially performed using an internal silicon reference at $500 \mathrm{~cm}^{-1}$ and gave a peak position resolution of less than $1 \mathrm{~cm}^{-1}$. The spectra were measured from 500 to $4500 \mathrm{~cm}^{-1}$. All samples were deposited onto glass slides in powdered form without using any solvent.

\section{Cell culture and exposure of cells to GO and EGFP-rGO}

Human embryonic kidney 293 cells were cultured in DMEM supplemented with 10\% FBS and $100 \mathrm{U} / \mathrm{mL}$ penicillin-streptomycin in a humidified incubator maintained at $37^{\circ} \mathrm{C}$ and $5 \% \mathrm{CO}_{2}$. At approximately $75 \%$ confluence, cells were harvested using $0.25 \%$ trypsin and subcultured in $75 \mathrm{~cm}^{2}$ flasks, 6-well plates, or 96-well plates depending on the intended use. Cells were allowed to attach to the substratum for $24 \mathrm{~h}$ prior to treatment. The medium was replaced three times per week, and cells were passaged at subconfluency. Cells were prepared in $100 \mu \mathrm{L}$ aliquots at a density of $1 \times 10^{5}$ / $\mathrm{mL}$ and plated in 96-well plates. After the cells were cultured for $24 \mathrm{~h}$, the medium was replaced with medium containing GO or EGFP-rGO at different concentrations $(0-100 \mu \mathrm{g} / \mathrm{mL})$. After incubation for an additional $24 \mathrm{~h}$, cells were analyzed for viability, lactate dehydrogenase (LDH) release, and reactive oxygen species (ROS) generation. Cells not exposed to GO or EGFP-rGO served as the control. Further, morphology of cells treated with GO or EGFP-rGO or untreated was examined using an OLYMPUS IX71 microscope (Japan) using appropriate filter sets. 


\section{Cell-viability assay}

The WST-8 assay was performed as described previously [29]. Typically, $1 \times 10^{4}$ cells were seeded in a 96-well plate and cultured in DMEM supplemented with 10\% FBS at $37^{\circ} \mathrm{C}$ under $5 \% \mathrm{CO}_{2}$. After $24 \mathrm{~h}$, the cells were washed with $100 \mu \mathrm{L}$ of serum-free DMEM two times and incubated with $100 \mu \mathrm{L}$ of different concentrations of GO or EGFP-rGO suspensions in serum-free DMEM. After $24 \mathrm{~h}$ of exposure, the cells were washed twice with serum-free DMEM, and $15 \mu \mathrm{L}$ of WST-8 solution was added to each well containing $100 \mu \mathrm{L}$ of serum-free DMEM. After $1 \mathrm{~h}$ of incubation at $37^{\circ} \mathrm{C}$ under $5 \% \mathrm{CO}_{2}$, $80 \mu \mathrm{L}$ of the mixture was transferred to another 96-well plate because residual GO or EGFP-rGO can affect the absorbance values at $450 \mathrm{~nm}$. The absorbance of the mixture solutions was measured at $450 \mathrm{~nm}$ using a micro plate reader. Cell-free control experiments were performed to determine whether GO and EGFP-rGO react directly with the WST-8 reagents. Typically, $100 \mu \mathrm{L}$ of GO or EGFP-rGO suspensions with different concentrations $(0-100 \mu \mathrm{g} / \mathrm{mL})$ were added to a 96 -well plate and $10 \mu \mathrm{L}$ of WST-8 reagent solution was added to each well; the mixture was incubated at $37^{\circ} \mathrm{C}$ under $5 \% \mathrm{CO}_{2}$ for $1 \mathrm{~h}$. After incubation, the GO or EGFP-rGO was centrifuged and $100 \mu \mathrm{L}$ of the supernatant was transferred to another 96-well plate. The optical density was measured at $450 \mathrm{~nm}$.

\section{Membrane integrity}

The cell membrane integrity of human embryonic kidney 293 cells was evaluated by determining the activity of lactate dehydrogenase (LDH) leaking out of the cells according to the manufacturer's instructions (in vitro toxicology assay kit, TOX7, Sigma, USA) and also as described previously [21]. Briefly, the cells were exposed to various concentrations of GO and EGFP-rGO (0$100 \mu \mathrm{g} / \mathrm{mL}$ ) for $24 \mathrm{~h}$, and then $100 \mu \mathrm{L}$ per well of each cell-free supernatant was transferred in triplicate into wells in a 96-well plate, and $100 \mu \mathrm{L}$ of the LDH assay reaction mixture was added to each well. After $3 \mathrm{~h}$ of incubation under standard conditions, the optical density of the color generated was determined at a wavelength of $490 \mathrm{~nm}$ using a micro plate reader.

\section{Determination of ROS}

ROS were estimated according to a method described previously [43]. Intracellular ROS were measured based on the intracellular peroxide-dependent oxidation of 2,7'-dichlorodihydrofluorescein diacetate (DCFH-DA, Molecular Probes, USA) to form the fluorescent compound 2,7'-dichlorofluorescein (DCF), as previously described. Cells were seeded onto 24-well plates at a density of $5 \times 10^{4}$ cells per well and cultured for $24 \mathrm{~h}$. After washing twice with PBS, fresh medium containing different concentrations of GO or EGFP-rGO (0$100 \mu \mathrm{g} / \mathrm{mL}$ ) was added and the cells were incubated for $24 \mathrm{~h}$. The cells were then supplemented with $20 \mu \mathrm{M}$ DCFH-DA, and incubation continued for $30 \mathrm{~min}$ at $37^{\circ} \mathrm{C}$. The cells were rinsed with PBS, $2 \mathrm{~mL}$ of PBS was added to each well, and the fluorescence intensity was determined using a spectrofluorometer (Gemini EM) with excitation at $485 \mathrm{~nm}$ and emission at $530 \mathrm{~nm}$.

\section{Statistical analyses}

All assays were carried out in triplicate and the experiments were repeated at least three times. The results are presented as means $\pm \mathrm{SD}$. All experimental data were compared using the Student's $t$ test. A p value less than 0.05 was considered statistically significant.

\section{Competing interests}

The authors declare that they have no competing interests.

\section{Authors' contributions}

SG conceived the idea and participated in the design, preparation of graphene, and writing of the manuscript. JWH performed the characterization of graphene. EK, JKP, DNK participated in culturing, biocompatibility, and other biochemical assays. SG and JHK participated in the coordination of the study. All authors read and approved the final manuscript.

\section{Acknowledgments}

This work was supported by the KU-Research Professor Program of Konkuk University. Dr Sangiliyandi Gurunathan was supported by a Konkuk University KU-Full-time Professorship. This work was also supported by the Woo Jang-Choon project (PJ007849).

\section{Author details}

${ }^{1}$ Department of Animal Biotechnology, Konkuk University, 1 Hwayang-Dong, Gwangin-gu, Seoul 143-701, South Korea. ${ }^{2}$ GS Institute of Bio and Nanotechnology, Coimbatore, Tamil Nadu 641024, India. ${ }^{3}$ Animal Biotechnology Division, National Institute of Animal Science, Suwon 441-350, Korea.

Received: 7 August 2014 Accepted: 26 September 2014

Published online: 03 October 2014

\section{References}

1. Novoselov KS, Jiang Z, Zhang Y, Morozov SV, Stormer HL, Zeitler U, Maan JC, Boebinger GS, Kim P, Geim AK: Room-temperature quantum Hall effect in graphene. Science 2007, 315:1379.

2. Rao CN, Sood AK, Subrahmanyam KS, Govindaraj A: Graphene: the new two-dimensional nanomaterial. Angew Chem Int Ed Engl 2009, 48:7752-7777.

3. Dreyer DR, Park S, Bielawski CW, Ruoff RS: The chemistry of graphene oxide. Chem Soc Rev 2010, 39:228-240.

4. Sanchez VC, Jachak A, Hurt RH, Kane AB: Biological interactions of graphene-family nanomaterials: an interdisciplinary review. Chem Res Toxicol 2012, 25:15-34.

5. Lu CH, Yang HH, Zhu CL, Chen X, Chen GN: A graphene platform for sensing biomolecules. Angew Chem Int Ed Engl 2009, 48:4785-4787.

6. Hu W, Peng C, Luo W, Lv M, Li X, Li D, Huang Q, Fan C: Graphene-based antibacterial paper. ACS Nano 2010, 4:4317-4323.

7. Akhavan O, Ghaderi E: Toxicity of graphene and graphene oxide nanowalls against bacteria. ACS Nano 2010, 4:5731-5736.

8. Gurunathan S, Han JW, Dayem AA, Eppakayala V, Kim JH: Oxidative stressmediated antibacterial activity of graphene oxide and reduced graphene oxide in Pseudomonas aeruginosa. Int J Nanomedicine 2012, 7:5901-5914.

9. Sun XM, Liu Z, Welsher K, Robinson JT, Goodwin A, Zaric S, Dai HJ: Nanographene oxide for cellular imaging and drug delivery. Nano Res 2008, 1:203-212. 
10. Nayak TR, Andersen H, Makam VS, Khaw C, Bae S, Xu X, Ee PL, Ahn JH, Hong $\mathrm{BH}$, Pastorin G, Ozyilmaz B: Graphene for controlled and accelerated osteogenic differentiation of human mesenchymal stem cells. ACS Nano 2011, 5:4670-4678.

11. Song Y, Qu K, Zhao C, Ren J, Qu X: Graphene oxide: intrinsic peroxidase catalytic activity and its application to glucose detection. Adv Mater 2010, 22:2206-2210

12. Wang L, Lee K, Sun YY, Lucking M, Chen ZF, Zhao JJ, Zhang SBB: Graphene oxide as an ideal substrate for hydrogen storage. ACS Nano 2009, 3:2995-3000.

13. Wang Y, Zhang P, Liu CF, Zhan L, Li YF, Huang CZ: Green and easy synthesis of biocompatible graphene for use as an anticoagulant. Rsc Adv 2012, 2:2322-2328.

14. Stankovich S, Dikin DA, Piner RD, Kohlhaas KA, Kleinhammes A, Jia Y, Wu Y, Nguyen ST, Ruoff RS: Synthesis of graphene-based nanosheets via chemical reduction of exfoliated graphite oxide. Carbon 2007, 45:1558-1565.

15. Cote $L$, Cruz-Silva R, Huang JX: Flash reduction and patterning of graphite oxide and its polymer composite. J Am Chem Soc 2009, 131:11027-11032.

16. Zhou Y, Bao QL, Tang LAL, Zhong YL, Loh KP: Hydrothermal dehydration for the "green" reduction of exfoliated graphene oxide to graphene and demonstration of tunable optical limiting properties. Chem Mater 2009, 21:2950-2956.

17. Hass J, de Heer WA, Conrad EH: The growth and morphology of epitaxia multilayer graphene. J Phys Condens Matter 2008, 20:323202 (27pp).

18. Akhavan O, Ghaderi E: Photocatalytic reduction of graphene oxide nanosheets on $\mathrm{TiO} 2$ thin film for photoinactivation of bacteria in solar light irradiation. J Phys Chem C 2009, 113:20214-20220.

19. Akhavan O, Abdolahad M, Esfandiar A, Mohatashamifar M: Photodegradation of graphene oxide sheets by $\mathrm{TiO} 2$ nanoparticles after a photocatalytic reduction. J Phys Chem C 2010, 114:12955-12959.

20. Akhavan O, Choobtashani M, Ghaderi E: Protein degradation and RNA efflux of viruses photocatalyzed by graphene-tungsten oxide composite under visible light irradiation. J Phys Chem C 2012, 116:9653-9659.

21. Gurunathan S, Han J, Park JH, Kim JH: An in vitro evaluation of graphene oxide reduced by Ganoderma spp. in human breast cancer cells (MDA-MB-231). Int J Nanomedicine 2014, 9:1783-1797.

22. Tang LAL, Lee WC, Shi H, Wong EYL, Sadovoy A, Gorelik S, Hobley J, Lim CT, Loh KP: Highly wrinkled cross-linked graphene oxide membranes for biological and charge-storage applications. Small 2012, 8:423-431.

23. Stankovich S, Piner RD, Chen XQ, Wu NQ, Nguyen ST, Ruoff RS: Stable aqueous dispersions of graphitic nanoplatelets via the reduction of exfoliated graphite oxide in the presence of poly(sodium 4-styrenesulfonate). J Mater Chem 2006, 16:155-158.

24. Min K, Han TH, Kim J, Jung J, Jung C, Hong SM, Koo CM: A facile route to fabricate stable reduced graphene oxide dispersions in various media and their transparent conductive thin films. J Colloid Interface Sci 2012, 383:36-42.

25. Fan XB, Peng WC, Li Y, Li XY, Wang SL, Zhang GL, Zhang FB: Deoxygenation of exfoliated graphite oxide under alkaline conditions: a green route to graphene preparation. Adv Mater 2008, 20:4490-4493.

26. Akhavan O, Bijanzad K, Mirsepah A: Synthesis of graphene from natural and industrial carbonaceous wastes. Rsc Adv 2014, 4:20441-20448.

27. Zhang Y, Ali SF, Dervishi E, Xu Y, Li Z, Casciano D, Biris AS: Cytotoxicity effects of graphene and single-wall carbon nanotubes in neural phaeochromocytoma-derived PC12 cells. ACS Nano 2010, 4:3181-3186.

28. Chang Y, Yang ST, Liu JH, Dong E, Wang Y, Cao A, Liu Y, Wang H: In vitro toxicity evaluation of graphene oxide on A549 cells. Toxicol Lett 2011, 200:201-210.

29. Wang K, Ruan J, Song H, Zhang JL, Wo Y, Guo SW, Cui DX: Biocompatibility of graphene oxide. Nanoscale Res Lett 2011, 6:8

30. Gurunathan S, Han JW, Eppakayala V, Dayem AA, Kwon DN, Kim JH: Biocompatibility effects of biologically synthesized graphene in primary mouse embryonic fibroblast cells. Nanoscale Res Lett 2013, 8:393.

31. Lu CH, Zhu CL, Li J, Liu JJ, Chen X, Yang HH: Using graphene to protect DNA from cleavage during cellular delivery. Chem Commun 2010, 46:3116-3118

32. Sasidharan A, Panchakarla LS, Chandran P, Menon D, Nair S, Rao CNR, Koyakutty M: Differential nano-bio interactions and toxicity effects of pristine versus functionalized graphene. Nanoscale 2011, 3:2461-2464.

33. Pan YZ, Bao HQ, Sahoo NG, Wu TF, Li L: Water-Soluble Poly(Nisopropylacrylamide)-Graphene sheets synthesized via click chemistry for drug delivery. Adv Funct Mater 2011, 21:2754-2763.
34. Fan HL, Wang LL, Zhao KK, Li N, Shi ZJ, Ge ZG, Jin ZX: Fabrication, mechanical properties, and biocompatibility of graphene-reinforced chitosan composites. Biomacromolecules 2010, 11:2345-2351.

35. Chen YF, Qi YY, Tai ZX, Yan XB, Zhu FL, Xue QJ: Preparation, mechanical properties and biocompatibility of graphene oxide/ultrahigh molecular weight polyethylene composites. Eur Polym J 2012, 48:1026-1033.

36. Akhavan O, Ghaderi E, Akhavan A: Size-dependent genotoxicity of graphene nanoplatelets in human stem cells. Biomaterials 2012, 33:8017-8025

37. Alzhavan O, Ghaderi E, Shahsavar M: Graphene nanogrids for selective and fast osteogenic differentiation of human mesenchymal stem cells. Carbon 2013, 59:200-211.

38. Akhavan O, Ghaderi E, Abouei E, Hatamie S, Ghasemi E: Accelerated differentiation of neural stem cells into neurons on ginseng-reduced graphene oxide sheets. Carbon 2014, 66:395-406.

39. Park SY, Park J, Sim SH, Sung MG, Kim KS, Hong BH, Hong S: Enhanced differentiation of human neural stem cells into neurons on graphene. Adv Mater 2011, 23:H263-+.

40. Lee WC, Lim CHYX, Shi H, Tang LAL, Wang Y, Lim CT, Loh KP: Origin of enhanced stem cell growth and differentiation on graphene and graphene oxide. ACS Nano 2011, 5:7334-7341.

41. Akhavan O, Ghaderi E: Flash photo stimulation of human neural stem cells on graphene/TiO2 heterojunction for differentiation into neurons. Nanoscale 2013, 5:10316-10326.

42. Akhavan $O$, Ghaderi E: Differentiation of human neural stem cells into neural networks on graphene nanogrids. J Mater Chem B 2013, 1:6291-6301

43. Fernandez-Merino MJ, Guardia L, Paredes JI, Villar-Rodil S, Solis-Fernandez P, Martinez-Alonso A, Tascon JMD: Vitamin C is an ideal substitute for hydrazine in the reduction of graphene oxide suspensions. J Phys Chem C 2010, 114:6426-6432

44. Gao J, Liu F, Liu YL, Ma N, Wang ZQ, Zhang X: Environment-friendly method to produce graphene that employs vitamin $C$ and amino acid. Chem Mater 2010, 22:2213-2218.

45. Zhu CZ, Guo SJ, Fang YX, Dong SJ: Reducing sugar: New functional molecules for the green synthesis of graphene nanosheets. ACS Nano 2010, 4:2429-2437

46. Liu JB, Fu SH, Yuan B, Li YL, Deng ZX: Toward a universal "adhesive nanosheet" for the assembly of multiple nanoparticles based on a protein-induced reduction/decoration of graphene oxide. J Am Chem Soc 2010, 132:7279-+

47. Wang GM, Qian F, Saltikov C, Jiao YQ, Li Y: Microbial reduction of graphene oxide by Shewanella. Nano Res 2011, 4:563-570.

48. Gurunathan S, Han JW, Eppakayala V, Kim JH: Microbial reduction of graphene oxide by Escherichia coli: a green chemistry approach. Colloid Surface B 2013, 102:772-777.

49. Akhavan $\mathrm{O}$, Ghaderi E: Escherichia coli bacteria reduce graphene oxide to bactericidal graphene in a self-limiting manner. Carbon 2012, 50:1853-1860

50. Gurunathan S, Han JW, Eppakayala V, Kim JH: Green synthesis of graphene and its cytotoxic effects in human breast cancer cells. Int J Nanomedicine 2013, 8:1015-1027.

51. Esfandiar A, Akhavan O, Irajizad A: Melatonin as a powerful bio-antioxidant for reduction of graphene oxide. J Mater Chem 2011, 21:10907-10914.

52. Pham TA, Kim JS, Kim JS, Jeong YT: One-step reduction of graphene oxide with L-glutathione. Colloid Surface A 2011, 384:543-548.

53. Gurunathan S, Han J, Kim JH: Humanin: a novel functional molecule for the green synthesis of graphene. Colloid Surface B 2013, 111:376-383.

54. Deepak V, Umamaheshwaran PS, Guhan K, Nanthini RA, Krithiga B, Jaithoon $\mathrm{NMH}$, Gurunathan S: Synthesis of gold and silver nanoparticles using purified URAK. Colloid Surface B 2011, 86:353-358.

55. Vallhov H, Qin J, Johansson SM, Ahlborg N, Muhammed MA, Scheynius A, Gabrielsson S: The importance of an endotoxin-free environment during the production of nanoparticles used in medical applications. Nano Lett 2006, 6:1682-1686.

56. Tsien RY: The green fluorescent protein. Annu Rev Biochem 1998, 67:509-544

57. Godwin AR, Stadler HS, Nakamura K, Capecchi MR: Detection of targeted GFP-Hox gene fusions during mouse embryogenesis. Proc Natl Acad Sci U S A 1998, 95:13042-13047.

58. Heim R, Prasher DC, Tsien RY: Wavelength mutations and posttranslational autoxidation of green fluorescent protein. Proc Natl Acad Sci U S A 1994, 91:12501-12504 
59. Rafat M, Cleroux CA, Fong WG, Baker AN, Leonard BC, O'Connor MD, Tsilfidis C: PEG-PLA microparticles for encapsulation and delivery of Tat-EGFP to retinal cells. Biomaterials 2010, 31:3414-3421.

60. Li X, Zhang G, Ngo N, Zhao X, Kain SR, Huang CC: Deletions of the Aequorea victoria green fluorescent protein define the minimal domain required for fluorescence. J Biol Chem 1997, 272:28545-28549.

61. Brocklehurst K, Little G: Reactivities of the various protonic states in the reactions of papain and of L-cysteine with 2,2 '- and with 4,4'- dipyridyl disulphide: evidence for nucleophilic reactivity in the un-ionized thiol group of the cysteine- 25 residue of papain occasioned by its interaction with the histidine-159-asparagine-175 hydrogen-bonded system. Biochem J 1972, 128:471-474.

62. Chen D, Li L, Guo L: An environment-friendly preparation of reduced graphene oxide nanosheets via amino acid. Nanotechnology 2011, 22:325601.

63. Hummers WS, Offeman RE: Preparation of graphitic oxide. J Am Chem Soc 1958, 80:1339-1339

64. Luo ZT, LU Y, Somers LA, Johnson ATC: High yield preparation of macroscopic graphene oxide membranes. J Am Chem Soc 2009, 131:898-+

65. Eda G, Chhowalla M: Chemically derived graphene oxide: towards largearea thin-film electronics and optoelectronics. Adv Mater 2010, 22:2392-2415

66. Zhang JL, Yang HJ, Shen GX, Cheng P, Zhang JY, Guo SW: Reduction of graphene oxide via L-ascorbic acid. Chem Commun 2010, 46:1112-1114.

67. Cheng C, Nie SQ, Li S, Peng H, Yang H, Ma L, Sun SD, Zhao CS: Biopolymer functionalized reduced graphene oxide with enhanced biocompatibility via mussel inspired coatings/anchors. J Mater Chem B 2013, 1:265-275.

68. Xu YX, Bai H, Lu GW, Li C, Shi GQ: Flexible graphene films via the filtration of water-soluble noncovalent functionalized graphene sheets. J Am Chem Soc 2008, 130:5856-+.

69. Choi EY, Han TH, Hong JH, Kim JE, Lee SH, Kim HW, Kim SO: Noncovalent functionalization of graphene with end-functional polymers. J Mater Chem 2010, 20:1907-1912.

70. Gurunathan S, Han JW, Park JH, Eppakayala V, Kim JH: Ginkgo biloba: a natural reducing agent for the synthesis of cytocompatible graphene. Int J Nanomedicine 2014, 9:363-377.

71. Talukdar Y, Rashkow JT, Lalwani G, Kanakia S, Sitharaman B: The effects of graphene nanostructures on mesenchymal stem cells. Biomaterials 2014 35:4863-4877.

72. Cheng C, Li S, Nie SQ, Zhao WF, Yang H, Sun SD, Zhao CS: General and biomimetic approach to biopolymer-functionalized graphene oxide nanosheet through adhesive dopamine. Biomacromolecules 2012, 13:4236-4246

73. Lammel T, Boisseaux P, Fernandez-Cruz ML, Navas JM: Internalization and cytotoxicity of graphene oxide and carboxyl graphene nanoplatelets in the human hepatocellular carcinoma cell line Hep G2. Part Fibre Toxicol 2013, 10:27

74. Liu SB, Zeng TH, Hofmann M, Burcombe E, Wei J, Jiang RR, Kong J, Chen Y Antibacterial activity of graphite, graphite oxide, graphene oxide, and reduced graphene oxide: membrane and oxidative stress. ACS Nano 2011, 5:6971-6980

75. Gurunathan S, Han JW, Kim JH: Green chemistry approach for the synthesis of biocompatible graphene. Int J Nanomedicine 2013, 8:2719-2732.

76. Yang F, Liu YQ, Gao LA, Sun J: pH-Sensitive highly dispersed reduced graphene oxide solution using lysozyme via an in situ reduction method. J Phys Chem C 2010, 114:22085-22091.

77. Zhou NL, Gu H, Tang FF, Li WX, Chen YY, Yuan J: Biocompatibility of novel carboxylated graphene oxide-glutamic acid complexes. J Mater Sci 2013, 48:7097-7103.

78. Prasanna K, Natarajan R, Kaveripatnam S, Dhathathreyan KS: Functionalized exfoliated graphene oxide as supercapacitor electrodes. Sci Res Pub 2012, 2:59-66.

79. Jeong HK, Lee YP, Lahaye RJWE, Park MH, An KH, Kim IJ, Yang CW, Park CY, Ruoff RS, Lee $\mathrm{YH}$ : Evidence of graphitic $A B$ stacking order of graphite oxides. J Am Chem Soc 2008, 130:1362-1366.

80. He HK, Gao C: General approach to individually dispersed, highly soluble, and conductive graphene nanosheets functionalized by nitrene chemistry. Chem Mater 2010, 22:5054-5064.

81. Lian PC, Zhu XF, Liang SZ, Li Z, Yang WS, Wang HH: Large reversible capacity of high quality graphene sheets as an anode material for lithium-ion batteries. Electrochim Acta 2010, 55:3909-3914
82. Wang $Y Y, N i Z H$, Shen $Z X$, Wang $H M$, Wu YH: Interference enhancement of Raman signal of graphene. Appl Phys Lett 2008, 92:043121.

83. Vernekar AA, Mugesh G: Hemin-functionalized reduced graphene oxide nanosheets reveal peroxynitrite reduction and isomerization activity. Chem-Eur J 2012, 18:15122-15132.

84. Tuinstra F, Koenig JL: Raman spectrum of graphite. J Chem Phys 1970 53:1126-1130.

85. Ferrari AC, Robertson J: Resonant Raman spectroscopy of disordered, amorphous, and diamondlike carbon. Phys Rev B 2001, 64:075414.

86. Fan ZJ, Kai W, Yan J, Wei T, Zhi LJ, Feng J, Ren YM, Song LP, Wei F: Facile synthesis of graphene nanosheets via Fe reduction of exfoliated graphite oxide. ACS Nano 2011, 5:191-198.

87. Lin ZY, Yao YG, Li Z, Liu Y, Li Z, Wong CP: Solvent-assisted thermal reduction of graphite oxide. J Phys Chem C 2010, 114:14819-14825.

88. Stankovich S, Dikin DA, Dommett GHB, Kohlhaas KM, Zimney EJ, Stach EA, Piner RD, Nguyen ST, Ruoff RS: Graphene-based composite materials. Nature 2006, 442:282-286.

89. Akhavan O, Ghaderi E, Aghayee S, Fereydooni Y, Talebi A: The use of a glucose-reduced graphene oxide suspension for photothermal cancer therapy. J Mater Chem 2012, 22:13773-13781.

90. Sim Y, Park J, Kim YJ, Seong MJ, Hong S: Synthesis of graphene layer using graphite dispersion in aqueous surfactant solutions. J Korean Phys Soc 2011, 58:938-942.

91. Green AA, Hersam MC: Solution phase production of graphene with controlled thickness via density differentiation. Nano Lett 2009, 9:4031-4036.

92. Kim YK, Kim MH, Min DH: Biocompatible reduced graphene oxide prepared by using dextran as a multifunctional reducing agent. Chem Commun 2011, 47:3195-3197.

93. Khanra P, Kuila T, Kim NH, Bae SH, Yu DS, Lee JH: Simultaneous biofunctionalization and reduction of graphene oxide by baker's yeast. Chem Eng J 2012, 183:526-533.

94. Gurunathan S, Han JW, Dayem AA, Eppakayala V, Park MR, Kwon DN, Kim $\mathrm{JH}$ : Antibacterial activity of dithiothreitol reduced graphene oxide. J Ind Eng Chem 2013, 19:1280-1288.

95. Shin HJ, Kim KK, Benayad A, Yoon SM, Park HK, Jung IS, Jin MH, Jeong HK, Kim JM, Choi JY, Lee YH: Efficient reduction of graphite oxide by sodium borohydride and its effect on electrical conductance. Adv Funct Mater 2009, 19:1987-1992

96. Thomas P, Smart TG: HEK293 cell line: a vehicle for the expression of recombinant proteins. J Pharmacol Toxicol Methods 2005, 51:187-200.

97. Hu WB, Peng C, Lv M, Li XM, Zhang YJ, Chen N, Fan CH, Huang Q: Protein corona-mediated mitigation of cytotoxicity of graphene oxide. ACS Nano 2011, 5:3693-3700

98. Kuila T, Bose S, Khanra P, Mishra AK, Kim NH, Lee JH: Recent advances in graphene-based biosensors. Biosens Bioelectron 2011, 26:4637-4648.

99. Feng LZ, Liu ZA: Graphene in biomedicine: opportunities and challenges. Nanomedicine 2011, 6:317-324.

100. Hong SW, Lee JH, Kang SH, Hwang EY, Hwang YS, Lee MH, Han DW, Park $J C$ : Enhanced neural cell adhesion and neurite outgrowth on graphenebased biomimetic substrates. Biomed Res Int 2014, Article ID 212149, 8 pages.

101. Yang K, Li YJ, Tan XF, Peng R, Liu Z: Behavior and toxicity of graphene and its functionalized derivatives in biological systems. Small 2013, 9:1492-1503.

102. Gurunathan S, Han JW, Eppakayala V, Kim JH: Biocompatibility of microbially reduced graphene oxide in primary mouse embryonic fibroblast cells. Colloids Surf B: Biointerfaces 2013, 105:58-66.

103. Reddy ARN, Reddy YN, Krishna DR, Himabindu V: Multi wall carbon nanotubes induce oxidative stress and cytotoxicity in human embryonic kidney (HEK293) cells. Toxicology 2010, 272:11-16.

104. Zhang YB, Xu Y, Li ZG, Chen T, Lantz SM, Howard PC, Paule MG, Slikker W, Watanabe F, Mustafa T, Biris AS, Ali SF: Mechanistic toxicity evaluation of uncoated and PEGylated single-walled carbon nanotubes in neuronal PC12 cells. ACS Nano 2011, 5:7020-7033.

105. Shvedova AA, Pietroiusti A, Fadeel B, Kagan VE: Mechanisms of carbon nanotube-induced toxicity: Focus on oxidative stress. Toxicol Appl Pharmacol 2012, 261:121-133.

106. Stern ST, Adiseshaiah PP, Crist RM: Autophagy and lysosomal dysfunction as emerging mechanisms of nanomaterial toxicity. Part Fibre Toxicol 2012, 9:20. 
107. Qu G, Wang X, Wang Z, Liu S, Jiang G: Cytotoxicity of quantum dots and graphene oxide to erythroid cells and macrophages. Nanoscale Res Lett 2013, 8:198.

108. Wu Q, Zhao Y, Zhao G, Wang D: microRNAs control of in vivo toxicity from graphene oxide in Caenorhabditis elegans. Nanomedicine 2014, doi:10.1016/.nano.2014.04.005.

109. Chong Y, Ma Y, Shen H, Tu X, Zhou X, Xu J, Dai J, Fan S, Zhang Z: The in vitro and in vivo toxicity of graphene quantum dots. Biomaterials 2014, 35:5041-5048.

110. Shen JF, Hu YH, Li C, Qin C, Ye MX: Synthesis of Amphiphilic graphene nanoplatelets. Small 2009, 5:82-85.

doi:10.1186/s12951-014-0041-9

Cite this article as: Gurunathan et al: Enhanced green fluorescent protein-mediated synthesis of biocompatible graphene. Journal of Nanobiotechnology 2014 12:41.

\section{Submit your next manuscript to BioMed Central and take full advantage of:}

- Convenient online submission

- Thorough peer review

- No space constraints or color figure charges

- Immediate publication on acceptance

- Inclusion in PubMed, CAS, Scopus and Google Scholar

- Research which is freely available for redistribution 